\title{
Gram-negative bacilli causing infections in an intensive care unit of a tertiary care hospital in Istanbul, Turkey
}

\author{
Seniha Senbayrak Akcay ${ }^{1}$, Asuman Inan ${ }^{1}$, Simin Cevan $^{2}$, Ayse Nilufer Ozaydin ${ }^{3}$, Naz Cobanoglu², Seyfi \\ Celik Ozyurek ${ }^{1}$, Sebahat Aksaray ${ }^{2}$ \\ ${ }^{1}$ Department of Infectious Diseases and Clinical Microbiology, Haydarpasa Numune Education and Research \\ Hospital, Uskudar, Istanbul, Turkey \\ ${ }^{2}$ Department of Microbiology and Clinical Microbiology, Haydarpasa Numune Education and Research Hospital, \\ Uskudar, Istanbul, Turkey \\ ${ }^{3}$ Department of Public Health, Marmara University, Faculty of Medicine, Uskudar, Istanbul, Turkey
}

\begin{abstract}
Introduction: This study aimed to demonstrate the changing epidemiology of infecting microorganisms and their long-term resistance profiles and to describe the microbiological point of view in anti-infective management of intensive care unit (ICU) patients.

Methodology: A total of 5,690 isolates of Gram-negative bacilli were included in this study. Antibiotic susceptibility was tested using the disk diffusion method and Vitek 2 system. Chi-square tests were used for hypothesis testing.

Results: The most frequently isolated organisms were A. baumannii (37.3\%), P. aeruginosa (30.3\%), Enterobacter spp. (10.4\%), E. coli $(10.4 \%)$, and Klebsiella spp. (8.9\%). A. baumannii was the most frequently isolated organism from the respiratory tract $(43.4 \%)$; the susceptibility rates for imipenem and meropenem decreased to $7 \%$ and $6 \%(\mathrm{p}<0.0001)$, respectively. The percentage of multidrug-resistant (MDR) A. baumannii isolates continuously increased from $18.7 \%$ in 2004 to $69 \%$ in $2011(\mathrm{p}<0.0001)$, whereas MDR P. aeruginosa isolates increased from $1.5 \%$ to $22 \%(\mathrm{p}<0.0001)$. Carbapenem-resistant Klebsiella isolates emerged in 2010 and increased to $20 \%$ in the next year. The rates of ESBL-producing Enterobacteriaceae in the ICU was very high in $2011-50 \%$ for E. coli and $80 \%$ for Klebsiella strains. Conclusion: The most common isolated Gram-negative bacillus in our study was A. baumannii and that the prevalence of MDR isolates has increased markedly over. Accordingly, the comparison of antibiotic resistance of other pathogens in 2004 and 2011 displayed an increasing trend. These data imply the urgent need for new and effective strategies in our hospital and in the region.
\end{abstract}

Key words: Gram-negative bacilli; Antibiotic resistance; ICU; MDR

J Infect Dev Ctries 2014; 8(5):597-604. doi:10.3855/jidc.4277

(Received 28 September 2013 - Accepted 27 December 2013)

Copyright $(\underset{2}{2014}$ Akcay et al. This is an open-access article distributed under the Creative Commons Attribution License, which permits unrestricted use, distribution, and reproduction in any medium, provided the original work is properly cited.

\section{Introduction}

Gram-negative bacilli (GNB) are a common cause of sepsis, pneumonia, and urinary tract infections in intensive care unit (ICU) patients [1-3]. Hospitalized patients in these areas often suffer from a debilitating physical condition, deficiencies of the immune system, and severe infectious complications including nosocomial infections requiring intense antibiotic therapy for long periods. These types of infections are not only difficult to treat, but also have a significant adverse economic impact on the healthcare system in terms of costs, increased length of hospital stay, morbidity, and mortality [3-5]. Antibiotic resistance among GNB are increasing continuously and this issue must be dealt with as a major worldwide issue [6-9]. As variations do exist among different countries and hospitals, the local resistance data is essential for appropriate initial therapy of ICU infections [10]. The aim of this study was to report the changing epidemiology of ICU pathogens and their long-term resistance profiles, and to provide a microbiological point of view in anti-infective management of ICU patients.

\section{Methodology}

Data was collected between January 2004 and December 2011 at the 21-bed mixed ICU of Haydarpasa Numune Education and Research Hospital (HNH), which has a 725 bed capacity. Patients who acquired infections after 48 hours of ICU admission were included in this study; diagnosis was made according to Centers for Disease Control and Prevention guidelines [11]. Ethical approval was granted from The Haydarpasa Numune Education and 
Research Hospital Ethical Committee (HNEAH$\mathrm{KAEK} / 27)$.

The clinical isolates of GNB recovered from tracheal aspirate, blood, and urine samples were analyzed, identified using standard microbiological techniques, and differentiated to species level by BBL Enteric/Nonfermenter ID Kit (Becton Dickinson, Franklin Lakes, USA) and Vitek2 system (bioMérieux, Marcy l'Etoile, France). Consecutive, non-duplicate, and clinical GNB isolates were collected.

Antibiotic susceptibility testing was performed using the Kirby-Bauer disk diffusion method according to Clinical and Laboratory Standards Institute (CLSI) criteria and microbroth dilution assay with the Vitek 2 system (bioMérieux, Marcy l'Etoile, France). The following antibiotics (Oxoid Disc) were tested: ampicillin/sulbactam, piperacillin/tazobactam, ceftriaxone, ceftazidime, cefoperazone/sulbactam, cefepime, gentamicin, amikacin, ciprofloxacin, levofloxacin, imipenem, and meropenem. Colistin entered the market in Turkey in 2009. The isolates were classified as susceptible, intermediate, or resistant according to the breakpoints established by the CLSI [12]. Breakpoints of cefoperazone/sulbactam were interpreted according to cefoperazone. Quality control was performed by testing Escherichia coli ATCC 25922, Pseudomonas aeruginosa ATCC 27853 and Klebsiella pneumoniae ATCC 700603. Extendedspectrum B-lactamase (ESBL) producers were detected using the CLSI double disk diffusion method. $A$. baumannii and $P$. aeruginosa were classified as multidrug-resistant (MDR) by non-susceptibility to at least one agent in three or more antibiotic classes [13].

Chi-square tests were used for hypothesis testing using SPSS version 11.0; OR and 95\% confidence intervals was calculated using EPI-INFO version 3.5.1 for statistical analysis. Differences were considered statistically significant at $\mathrm{p}$-values $<0.05$.

\section{Results}

A total of 5,690 isolates of GNB were identified between 2004 and 2011. Respiratory tracts (4,351, $76.5 \%)$, blood cultures $(690,12.1 \%)$ and urine (649, $11.4 \%$ ) were the major sources of the isolates (Table 1). The organisms most frequently isolated were $A$. baumannii $(2,124,37.3 \%), P$. aeruginosa $(1,736$, 30.3\%), Enterobacter spp. (594, 10.4\%), E. coli (592, 10.4\%), and Klebsiella spp. (509, 8.9\%).

Table 1. Distribution of isolates among samples

\begin{tabular}{lccccccccc}
\hline Samples & $\mathbf{2 0 0 4}$ & $\mathbf{2 0 0 5}$ & $\mathbf{2 0 0 6}$ & $\mathbf{2 0 0 7}$ & $\mathbf{2 0 0 8}$ & $\mathbf{2 0 0 9}$ & $\mathbf{2 0 1 0}$ & $\mathbf{2 0 1 1}$ & Total \\
\hline Respiratory tract & 267 & 379 & 447 & 511 & 535 & 785 & 755 & 672 & $\mathbf{4 , 3 5 1}$ \\
Blood & 30 & 45 & 73 & 105 & 112 & 129 & 98 & 98 & $\mathbf{6 9 0}$ \\
Urine & 102 & 102 & 91 & 64 & 72 & 85 & 72 & 61 & $\mathbf{6 4 9}$ \\
Total & $\mathbf{3 9 9}$ & $\mathbf{5 2 6}$ & $\mathbf{6 1 1}$ & $\mathbf{6 8 0}$ & $\mathbf{7 1 9}$ & $\mathbf{9 9 9}$ & $\mathbf{9 2 5}$ & $\mathbf{8 3 1}$ & $\mathbf{5 , 6 9 0}$ \\
\hline
\end{tabular}

Table 2. Distribution of GNB isolates among samples between 2004 and 2011

\begin{tabular}{|c|c|c|c|c|c|c|c|c|c|c|}
\hline $\begin{array}{l}\text { Organisms most } \\
\text { frequently isolated }\end{array}$ & Samples & 2004 & 2005 & 2006 & 2007 & 2008 & 2009 & 2010 & 2011 & Total \\
\hline \multirow{3}{*}{ A. baumannii } & Res.tract & 53 & 128 & 244 & 207 & 267 & 356 & 339 & 295 & 1,889 \\
\hline & Blood & 4 & 9 & 21 & 25 & 27 & 36 & 27 & 25 & 174 \\
\hline & Urine & 6 & 8 & 3 & 9 & 10 & 12 & 8 & 5 & 61 \\
\hline \multirow{3}{*}{ P. aeruginosa } & Res.tract & 105 & 146 & 98 & 186 & 164 & 279 & 223 & 192 & 1,393 \\
\hline & Blood & 6 & 9 & 11 & 27 & 24 & 31 & 19 & 12 & 153 \\
\hline & Urine & 46 & 44 & 31 & 12 & 13 & 14 & 17 & 13 & 190 \\
\hline \multirow{3}{*}{ Enterobacter spp. } & Res.tract & 45 & 47 & 57 & 45 & 40 & 47 & 52 & 43 & 376 \\
\hline & Blood & 12 & 9 & 17 & 22 & 28 & 21 & 14 & 11 & 134 \\
\hline & Urine & 11 & 11 & 8 & 17 & 15 & 12 & 6 & 4 & 84 \\
\hline \multirow{3}{*}{ E. coli } & Res.tract & 25 & 38 & 15 & 49 & 40 & 52 & 33 & 28 & 280 \\
\hline & Blood & 2 & 2 & 4 & 17 & 14 & 19 & 14 & 12 & 84 \\
\hline & Urine & 28 & 30 & 36 & 19 & 27 & 38 & 28 & 22 & 228 \\
\hline \multirow{3}{*}{ Klebsiella spp. } & Res.tract & 8 & 14 & 16 & 17 & 22 & 49 & 102 & 104 & 332 \\
\hline & Blood & 3 & 8 & 11 & 11 & 14 & 20 & 22 & 32 & 121 \\
\hline & Urine & 5 & 2 & 6 & 5 & 6 & 8 & 11 & 13 & 56 \\
\hline \multirow{3}{*}{ Others } & Res.tract & 31 & 6 & 17 & 7 & 2 & 2 & 6 & 10 & 81 \\
\hline & Blood & 3 & 8 & 9 & 3 & 5 & 2 & 2 & 6 & 65 \\
\hline & Urine & 6 & 7 & 7 & 2 & 1 & 1 & 2 & 4 & 30 \\
\hline Total & & 399 & 526 & 611 & 680 & 719 & 999 & 925 & 831 & 5,690 \\
\hline
\end{tabular}


Table 3. Trends in antibiotic resistance among various GNB between 2004 and 2011

\begin{tabular}{|c|c|c|c|c|c|c|c|c|c|c|c|}
\hline \multirow[b]{2}{*}{ Pathogen } & \multirow[b]{2}{*}{ Antibiotic } & \multicolumn{9}{|c|}{ Resistance rates (\%) } & \multirow[b]{2}{*}{ Trend } \\
\hline & & 2004 & 2005 & 2006 & 2007 & 2008 & 2009 & 2010 & 2011 & $\mathbf{p}$ & \\
\hline \multirow{9}{*}{ A. baumannii } & Imipenem & 21.9 & 35.2 & 64.9 & 50.2 & 71.1 & 76.0 & 89.0 & 92.9 & $<0.0001$ & $\uparrow \uparrow$ \\
\hline & Meropenem & 23.4 & 28.3 & 64.9 & 50.2 & 65.1 & 81.9 & 92.0 & 94.2 & $<0.0001$ & $\uparrow$ \\
\hline & Ampicilin-sulbactam & 48.4 & 20.0 & 98.1 & 83.0 & 79.9 & 85.9 & 97.1 & 95.1 & $<0.0001$ & $\uparrow$ \\
\hline & Gentamicin & 71.9 & 49.7 & 82.1 & 80.1 & 55.9 & 53.0 & 38.0 & 63.1 & $<0.0001$ & $\downarrow$ \\
\hline & Amikacin & 37.5 & 30.3 & 50.0 & 44.8 & 57.9 & 75.0 & 75.9 & 70.2 & $<0.0001$ & $\uparrow$ \\
\hline & Ceftazidime & 98.4 & 91.0 & 99.3 & 97.1 & 95.7 & 98.0 & 98.1 & 99.1 & $0.427^{\mathrm{a}}$ & - \\
\hline & Cefoperazone-sulbactam & 1.6 & 4.1 & 5.2 & 9.1 & 25.0 & 58.9 & 79.9 & 92.0 & $<0.0001$ & $\uparrow$ \\
\hline & Ciprofloxacin & 92.2 & 61.4 & 73.1 & 55.6 & 65.1 & 90.1 & 90.1 & 98.2 & $<0.0001$ & $\uparrow$ \\
\hline & Levofloxacin & 90.6 & 66.9 & 67.2 & 63.9 & 71.1 & 85.9 & 88.0 & 96.9 & $<0.0001$ & $\uparrow$ \\
\hline \multirow[t]{8}{*}{ P. aeruginosa } & Imipenem & 24.8 & 24.1 & 25.0 & 50.2 & 30.8 & 46.0 & 62.2 & 48.8 & $<0.0001$ & $\uparrow$ \\
\hline & Meropenem & 24.8 & 21.1 & 22.9 & 50.2 & 41.8 & 51.2 & 56.0 & 46.1 & $<0.0001$ & $\uparrow$ \\
\hline & Piperacilin-tazobactam & 47.8 & 48.2 & 35.7 & 42.2 & 22.9 & 44.1 & 57.9 & 56.2 & 0.004 & $\uparrow$ \\
\hline & Gentamicin & 73.2 & 71.9 & 70.7 & 72.0 & 42.8 & 71.9 & 50.2 & 31.8 & $<0.0001$ & $\uparrow$ \\
\hline & Amikacin & 1.9 & 3.0 & 27.9 & 32.0 & 19.9 & 48.1 & 20.8 & 23.0 & 0.254 & - \\
\hline & Ceftazidime & 33.8 & 74.9 & 85.7 & 82.2 & 79.6 & 96.0 & 91.9 & 53,0 & 0.001 & $\downarrow$ \\
\hline & Ciprofloxacin & 72.0 & 71.9 & 67.9 & 64.0 & 62.7 & 71.9 & 59.1 & 47.9 & $<0.0001$ & $\uparrow$ \\
\hline & Levofloxacin & 82.8 & 74.9 & 84.3 & 54.2 & 75.6 & 84.0 & 69.1 & 59.0 & 0.001 & $\uparrow$ \\
\hline \multirow{11}{*}{ Klebsiella spp. } & Imipenem & 0 & 0 & 0 & 0 & 0 & 0 & 5.0 & 20.0 & - & $*$ \\
\hline & Meropenem & 0 & 0 & 0 & 0 & 0 & 0 & 7.0 & 19.0 & - & $*$ \\
\hline & Piperacilin-tazobactam & 18.8 & 20.8 & 18.2 & 21.2 & 64.3 & 63.6 & 79.3 & 75.8 & $<0.0001$ & $\uparrow$ \\
\hline & Gentamicin & 18.8 & 20.8 & 15.2 & 21.2 & 11.9 & 18.2 & 30.4 & 44.3 & $<0.0001^{\mathrm{b}}$ & $\uparrow$ \\
\hline & Amikacin & 12.5 & 16.7 & 15.2 & 15.2 & 33.3 & 14.3 & 24.4 & 28.9 & $0.043^{\mathrm{b}}$ & $\uparrow$ \\
\hline & Ceftazidime & 81.3 & 83.3 & 90.9 & 93.9 & 76.2 & 88.3 & 90.4 & 80.5 & $0.305^{\mathrm{b}}$ & - \\
\hline & Ceftriaxone & 93.8 & 91.7 & 90.9 & 97.0 & 78.6 & 88.3 & 92.6 & 89.9 & $0.854^{\mathrm{c}}$ & - \\
\hline & Cefepime & 50.0 & 58.3 & 69.7 & 90.9 & 76.2 & 31.2 & 90.4 & 79.9 & $0.035^{\mathrm{d}}$ & $\uparrow$ \\
\hline & Cefoperazone-sulbactam & 31.3 & 25.0 & 21.2 & 24.2 & 50.0 & 44.2 & 60.0 & 59.1 & $<0.0001$ & $\uparrow$ \\
\hline & Ciprofloxacin & 37.5 & 79.2 & 63.6 & 66.7 & 54.8 & 22.1 & 26.7 & 63.8 & 0.132 & - \\
\hline & Levofloxacin & 31.3 & 70.8 & 57.6 & 72.7 & 81.0 & 18.2 & 16.3 & 77.2 & 0.838 & - \\
\hline \multirow[t]{11}{*}{ Enterobacter spp. } & Imipenem & 0 & 0 & 0 & 0 & 0 & 0 & 0 & 0 & - & - \\
\hline & Meropenem & 0 & 0 & 0 & 0 & 0 & 0 & 0 & 0 & - & - \\
\hline & Piperacilin-tazobactam & 38.2 & 31.3 & 25.6 & 57.1 & 55.4 & 48.8 & 63.9 & 41.4 & $<0.0001$ & $\uparrow$ \\
\hline & Gentamicin & 16.2 & 13.4 & 18.3 & 22.6 & 18.1 & 33.8 & 19.4 & 36.2 & 0.002 & $\uparrow$ \\
\hline & Amikacin & 10.4 & 7.5 & 12.2 & 11.9 & 21.7 & 7.5 & 19.4 & 10.3 & 0.252 & - \\
\hline & Ceftazidime & 50.0 & 62.7 & 53.7 & 44.0 & 71.1 & 67.5 & 77.4 & 62.1 & 0.002 & $\uparrow$ \\
\hline & Ceftriaxone & 54.4 & 65.7 & 52.4 & 65.5 & 91.6 & 72.5 & 77.8 & 70.7 & $<0.0001$ & $\uparrow$ \\
\hline & Cefepime & 54.4 & 58.2 & 46.3 & 46.4 & 57.8 & 42.5 & 73.6 & 58.6 & 0.161 & - \\
\hline & Cefoperazone-sulbactam & 14.7 & 28.4 & 22.0 & 23.8 & 44.6 & 43.8 & 47.2 & 29.3 & $<0.0001$ & $\uparrow$ \\
\hline & Ciprofloxacin & 20.6 & 25.4 & 35.4 & 53.6 & 48.2 & 45.0 & 15.3 & 29.3 & 0.618 & - \\
\hline & Levofloxacin & 22.1 & 32.8 & 28.8 & 46.4 & 55.4 & 42.5 & 13.9 & 29.3 & 0.767 & - \\
\hline \multirow[t]{11}{*}{ E. coli } & Imipenem & 0 & 0 & 0 & 0 & 0 & 0 & 0 & 0 & - & - \\
\hline & Meropenem & 0 & 0 & 0 & 0 & 0 & 0 & 0 & 0 & - & - \\
\hline & Piperacilin-tazobactam & 20.0 & 24.3 & 41.8 & 22.4 & 9.9 & 31.2 & 32.0 & 25.8 & 0.478 & - \\
\hline & Gentamicin & 20.0 & 15.7 & 50.9 & 36.5 & 32.1 & 44.0 & 26.7 & 27.4 & 0.173 & - \\
\hline & Amikacin & 7.3 & 1.4 & 10.9 & 5.9 & 9.9 & 3.7 & 4.0 & 6.5 & - & $*$ \\
\hline & Ceftazidime & 76.4 & 70.0 & 70.9 & 57.6 & 82.7 & 74.3 & 61.3 & 51.6 & 0.040 & $\uparrow$ \\
\hline & Ceftriaxone & 78.2 & 71.4 & 78.2 & 60.0 & 82.7 & 75.2 & 62.7 & 53.2 & 0.016 & $\uparrow$ \\
\hline & Cefepime & 61.8 & 68.6 & 70.9 & 56.5 & 75.3 & 73.4 & 58.7 & 50.0 & 0.262 & - \\
\hline & Cefoperazone-sulbactam & 3.6 & 7.1 & 10.9 & 14.1 & 14.8 & 20.2 & 22.7 & 21.0 & $<0.0001$ & $\uparrow$ \\
\hline & Ciprofloxacin & 58.2 & 61.4 & 69.1 & 49.4 & 74.1 & 67.0 & 54.7 & 51.6 & 0.577 & - \\
\hline & Levofloxacin & 54.5 & 41.4 & 76.4 & 69.4 & 75.3 & 62.4 & 54.7 & 50.0 & 0.914 & - \\
\hline
\end{tabular}

The $p$ value in the table shows the result of the Chi-square test linear-by-linear Association

The Chi-square test statistic is calculated for all years that have expected frequencies $\geq 5$

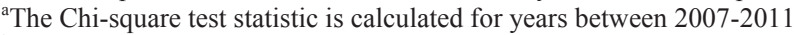

${ }^{\mathrm{b}}$ The Chi-square test statistic is calculated for years between 2005-2011

${ }^{\mathrm{c}}$ The Chi-square test statistic is calculated for years between 2009-2011

${ }^{\mathrm{d}}$ The Chi-square test statistic is calculated for years between 2006-2011

*The Chi-square test statistic is not calculated as all years had expected frequencies $<5$ 
Figure 1. Resistance rates of A. baumannii

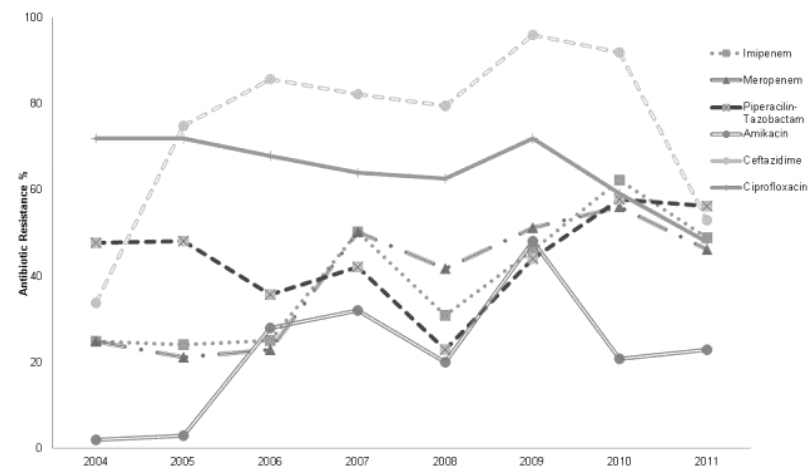

Figure 2. Resistance rates of $P$. aeruginosa

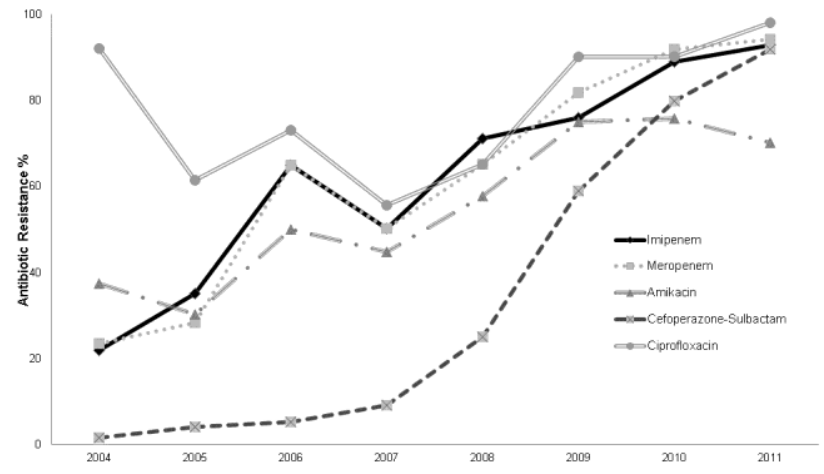

Table 4. Comparison of 2004 and 2011 antibiotic resistance of $A$. baumannii

\begin{tabular}{cccccc}
\hline Antibiotic & Resistance (\%) & Resistance (\%) & p value & OR & 95\% CI \\
& $\mathbf{2 0 0 4}$ & $\mathbf{2 0 1 1}$ & $<0.0001$ & 0.02 & $0.04-0.11$ \\
IMP & 21.9 & 92.9 & $<0.0001$ & 0.02 & $0.04-0.11$ \\
MEM & 23.4 & 94.2 & $<0.0001$ & 0.26 & $0.21-0.52$ \\
AK & 37.5 & 70.2 & $<0.0001$ & 0.00 & $0.00-0.03$ \\
CES & 1.6 & 92.0 & 0.021 & 0.22 & $0.17-0.68$ \\
CIP & 92.2 & 98.2 &
\end{tabular}

IMP: imipenem; MEM: meropenem; AK: amikacin; CES: cefoperazone-sulbactam; CIP: ciprofloxacin

Statistical analyses were calculated using EPI-INFO version 3.5.1

Table 5. Comparison of 2004 and 2011 antibiotic resistance of $P$. aeruginosa

\begin{tabular}{cccccc}
\hline Antibiotic & Resistance (\%) & Resistance (\%) & p value & OR & 95\% CI \\
\hline IMP & $\mathbf{2 0 0 4}$ & $\mathbf{2 0 1 1}$ & $<0.0001$ & 0.35 & $0.22-0.39$ \\
MEM & 24.8 & 48.8 & $<0.0001$ & 0.39 & $0.42-0.75$ \\
TZP & 24.8 & 46.1 & 0.106 & 0.71 & $0.65-1.04$ \\
AK & 47.8 & 56.2 & $<0.0001$ & 0.07 & $0.04-0.36$ \\
CAZ & 1.9 & 23.0 & $<0.0001$ & 0.45 & $0.48-0.81$ \\
CIP & 33.8 & 53.0 & $<0.0001$ & 2.79 & $1.40-2.46$ \\
\hline
\end{tabular}

IMP: imipenem; MEM: meropenem; TZP: tazobactam-piperacilin; AK: smikacin; CAZ: ceftazidime; CIP: ciprofloxacin

Statistical analyses were calculated using EPI-INFO version 3.5.1 
A. baumannii was the most commonly isolated organism from respiratory tracts $(1,889,43.4 \%)$ and blood cultures $(174,25.2 \%)$, while E. coli was the most frequently isolated organism from urine (228, 35.1\%) (Table 2).

There was a significant increasing trend in the percentage of $A$. baumannii isolated from the respiratory tract, while a decreasing trend in the percentage of $P$. aeruginosa was observed when counts of 2004 to 2011 were compared (Chi-square: $15,796 \mathrm{p}<0.0001)$. The antimicrobials tested and the percentages of isolates determined to be resistant are listed in Table 3. All of $A$. baumannii and $P$. aeruginosa isolates were susceptible to colistin.

\section{A. baumannii}

Rates of resistance to most antibiotics were significantly increased among $A$. baumannii during the study period (Table 3, Figure 1). The susceptibility of imipenem and meropenem in A. baumannii isolates markedly dropped from $78.1 \%$ and $76.6 \%$ to $7.1 \%$ and $5.8 \%$, respectively. A similar decline in susceptibility was observed for amikacin. Gentamicin and fluoroquinolone resistance rates had fluctuations, while ceftazidime showed no difference. The comparison of the resistance rates in the first year (2004) and in the last year (2011) showed a remarkable increase for imipenem, meropenem, amikacin, and cefoperazone-sulbactam, as seen in Table 4. The percentage of MDR isolates continuously increased from $18.7 \%$ (2004) to $69 \%$ (2011) (p < 0.0001).

\section{P. aeruginosa}

The resistance for imipenem, meropenem, and amikacin for $P$. aeruginosa isolates increased, as seen in Figure 2 and Table 3. The imipenem resistance rate was higher in $2010(62.2 \%)$ compared to the previous study years. Piperacillin-tazobactam had fluctuations in susceptibility. Interestingly, the increasing resistance rates to ceftazidime dropped from $96 \%$ in 2009 to $53 \%$ in 2011. Gentamicin and fluoroquinolone resistance rates fluctuated but decreased in 2011. When 2004 was compared to 2011 for piperacillintazobactam, no difference other than ciprofloxacin was observed, as shown in Table 5. The percentage of MDR isolates increased from $1.5 \%$ in 2004 to $22 \%$ in $2011(\mathrm{p}<0.0001)$.

\section{Enteric Gram negative bacilli}

The most active agents against E. coli and Enterobacter spp. were imipenem and meropenem; their susceptibility profiles remained stable over the eight years and no resistant isolate was detected. Until 2009, there were no isolates resistant to carbapenems for Klebsiella spp. (Table 3), but the resistance rate was $20 \%$ in 2011. Amikacin and gentamicin showed good in vitro activity against $E$. coli, but resistance rates for Klebsiella spp. increased. The resistance rates of $E$. coli to ciprofloxacin and levofloxacin were around $40 \%-50 \%$ during the study period, and reached to a peak level of $75 \%$ in 2008 . The susceptibility patterns of ciprofloxacin and levofloxacin for Klebsiella isolates had fluctuations, but decreased significantly in the last year. Decreases in the percentage of isolates susceptible to ciprofloxacin were also seen with Klebsiella spp. (62.5\% to $36.2 \%)$ and Enterobacter spp. (79.4\% to $70.7 \%)$. Cefoperazone/sulbactam and piperacillin/tazobactam showed higher activity against E. coli and Enterobacter spp. than against Klebsiella spp. High rates of resistance to third-generation cephalosporins were observed among isolates of Enterobacteriaceae. The percentage of ESBL-producing Klebsiella strains remained remarkably high (above 80\%) in 2004 through 2011; the percentage of ESBL-producing $E$. coli strains also remained high but fluctuated and decreased from $75.8 \%$ to $50 \%$.

\section{Discussion}

This eight-year surveillance study aimed to evaluate the antibiotic resistance patterns and changes among GNB recovered from ICU patients with infections in a Turkish hospital. An active patient surveillance database for hospital infections in targeted clinics has been maintained since 2003 in our hospital. We found that more than three-quarters of GNB isolates were recovered from clinical respiratory specimens in the ICU (Tables 1, 2). The remaining quarter of the microbiological samples included blood and urine specimens. Lockhart et al. reported that source of the GNB isolates from ICU patients in hospitals in the United States were as follows: the respiratory tract $(52.1 \%)$, urine $(17.3 \%)$, and blood $(14.2 \%)$ [2]. In a study from China, the authors found that most of the GNB isolates (61.2\%) were from the respiratory tract [14].

In our study, $A$. baumannii and $P$. aeruginosa were the most common microorganisms isolated from ICU patients, similar to what has described by the Turkish hospital infection surveillance system [15]. The spectrum of pathogens in ICUs may change from country to country with time and by hospital, type of ICU, and specific patient population [15-20]. 
During the eight-year period, isolation of $A$. baumannii, which was the most common agent from respiratory tract samples, increased remarkably. We previously documented that most of the healthcare associated infections in our ICU were ventilatorassociated pneumonia caused by A. baumannii [21]. The most frequent GNB isolated from respiratory tract samples differ greatly among hospitals in Turkey $[15,22]$.

The high resistance rates may be associated with antibiotic abuse and prolonged ICU stays [23]. Our data indicate an alarming pattern of antibiotic resistance in the majority of ICU isolates. The most dramatic change was observed for A. baumannii; the isolates showed an increasing trend of resistance to most antibiotics. No antibiotic tested in this study was effective enough to produce $>30 \%$ susceptibility for A. baumannii isolates except colistin. Accordingly, the resistance for imipenem, meropenem, and amikacin increased over time. On the other hand, $P$. aeruginosa resistance rates were lower overall than $A$. baumannii resistance rates for the antibiotics tested. In 2011, the resistance rate of $P$. aeruginosa to piperacillin/tazobactam slightly increased, while ciprofloxacin resistance decreased compared to 2004.

The resistance of $A$. baumannii to commonly used antibiotics has become a widespread and serious problem in ICUs of Turkey [21]. Carbapenem resistance in A. baumannii was seen in three-fourths of the isolates, while $P$. aeruginosa was reported to be resistant in one-third of the strains according to the Turkish National Hospital Infection Surveillance Network Report [15]. Other Turkish investigators have reported relatively lower rates of resistance (50\%-87\%) to carbapenems in A. baumannii [24-27]. Other studies reported similar resistance rates of $P$. aeruginosa [24,25]. In contrast to our results, the resistance rates of $A$. baumannii and $P$. aeruginosa are low in many developed countries [2,17]. P. aeruginosa and $A$. baumannii isolated from centers in the United States in the MYSTIC program (1999-2008) were characterized by higher susceptibilities to meropenem $85.4 \%$ and $45.7 \%$, respectively [28]. The susceptibility results from MYSTIC Europe 2007 were also higher than our rates [29]. Treatment options for carbapenemresistant $A$. baumannii infections are limited, and agents such as empirical colistin are now being considered in our ICU.

We observed a significant increase in resistance trend to ceftazidime, ceftriaxone, piperacillintazobactam, and cefoperazone-sulbactam among Enterobacteriacea isolates, but amikacin was broadly active. One of the most important observations from our study was the decrease of ciprofloxacin susceptibility for Enterobacteriacea over the study period. Overall fluoroquinolone usage is strongly linked to the emergence of fluoroquinolone resistance among GNB, and once established, resistance rates increase with increased usage [2]. Except for some Klebsiella strains, all enteric GNB were susceptible to carbapenems. Carbapenem-resistant Klebsiella spp. isolates emerged in 2010 in our ICU and have increased to $20 \%$. Leblebicioglu et al. reported a $6 \%$ resistance rate to carbapenems [25]. These observations are consistent with the results of other surveillance studies from Turkey [15,24], and suggest that carbapenems are still effective against Enterobacteriaceae; nevertheless, consideration should be given to carbapenamase-producing isolates, owing to their emergence and dissemination potential. In fact, the increased use of carbapenems to combat the growing prevalence of multidrug resistance, particularly ESBL-producing strains, shows early signs of eroding carbapenem effectiveness [30,31].

An alarming finding is the increase in resistance to third-generation cephalosporins and the increasing prevalence of ESBL-producing Enterobacteriaceae. Our rates for ESBL-production were $50 \%$ for E. coli and $80 \%$ for Klebsiella spp. in 2011. These observations are consistent with the results of other recent surveillance studies from Turkish hospitals and developing countries [7,32,33]. In contrast, the prevalence of ESBL-producing $E$. coli and $K$. pneumoniae in Sweden was $3.9 \%$ and $14.3 \%$ respectively [34]. The rate for K. pneumoniae was $8 \%$ in the Netherlands [31].

MDR increased to $92 \%$ of $A$. baumanni and $45 \%$ of $P$. aeruginosa isolates at the end of the study period. Accordingly, the increasing prevalence of MDR GNB in our ICU was disturbing. This trend towards increasing rates of MDR GNB has also been observed in several other studies of more limited scope than ours $[26,30,35]$. The reason that MDR and ESBLproduction rates are higher in our ICU is not exactly clear. Test isolates were not routinely available to us for ancillary molecular characterization of either resistance determinants or clonal relationships. Considering the status of antibiotic abuse in Turkey, the continuation of the present trend of resistance to antibiotics among GNB seems inevitable.

\section{Conclusion}

Our study showed that the prevalence of resistance was quite problematic in the ICU. The most 
frequently isolated GNB was A. baumannii, which shows a high MDR phenotype. Only colistin is an effective treatment. The extraordinary resistance rates seen in the ICU may be associated with deficiencies in infrastructure, understaffing, antibiotic abuse, and the prolonged ICU stays of patients. Thus, collaboration between ICU doctors and infectious diseases specialists is of great importance in Turkey [36]. The lack of any new compounds in the near future indicates that national, regional, and local surveillance efforts are imperative to provide clinicians with information for choosing empirical therapy. We believe these surveillance studies are helpful for planning more effective infection control policies and rational antibiotic therapy, and can reduce infectionrelated costs, morbidity, and mortality.

\section{References}

1. Rhomberg PR, Fritsche TR, Sader HS, Jones RN (2006) Antimicrobial susceptibility pattern comparisons among intensive care unit and general ward Gram-negative isolates from the Meropenem Yearly Susceptibility Test Information Collection Program (USA). Diagn Microbiol Infect Dis 56: 57-62.

2. Lockhart SR, Abramson MA, Beekmann SE, Gallagher G, Riedel S, Diekema DJ, Quinn JP, Doern GV (2007) Antimicrobial resistance among Gram-negative bacilli causing infections in intensive care unit patients in the United States between 1993 and 2004. J Clin Microbiol 45: 33523359 .

3. Vincent JL (2003) Nosocomial infections in adult intensivecare units. Lancet 361: 2068-2077.

4. Gastmeier P, Geffers C, Brandt C, Zuschneid I, Sohr D, Schwab F, Behnke M, Daschner F, Ruden H (2006) Effectiveness of a nationwide nosocomial infection surveillance system for reducing nosocomial infections. J Hosp Infect 64: 16-22.

5. Erdem H, Tekin-Koruk S, Koruk I, Tozlu-Keten D, Ulu-Kilic A, Oncul O, Guner R, Birengel S, Mert G, Nayman-Alpat S, Eren-Tulek N, Demirdal T, Elaldi N, Ataman-Hatipoglu C, Yilmaz E, Mete B, Kurtaran B, Ceran N, Karabay O, Inan D, Cengiz M, Sacar S, Yucesoy-Dede B, Yilmaz S, Agalar C, Bayindir Y, Alpay Y, Tosun S, Yilmaz H, Bodur H, Erdem HA, Dikici N, Dizbay M, Oncu S, Sezak N, Sari T, Sipahi OR, Uysal S, Yeniiz E, Kaya S, Ulcay A, Kurt H, Besirbellioglu BA, Vahaboglu H, Tasova Y, Usluer G, Arman D, Diktas H, Ulusoy S, Leblebicioglu H (2011) Assessment of the requisites of microbiology based infectious disease training under the pressure of consultation needs. Ann Clin Microbiol Antimicrob 10: 38.

6. Chopra I, Schofield C, Everett M, O'Neill A, Miller K, Wilcox M, Frere JM, Dawson M, Czaplewski L, Urleb U, Courvalin P (2008) Treatment of health-care-associated infections caused by Gram-negative bacteria: a consensus statement. Lancet Infect Dis 8: 133-139.

7. Erdem H, Akova M (2012) Leading infectious diseases problems in Turkey. Clin Microbiol Infect 18: 1056-1067.

8. Erdem H, Kilic S, Pahsa A, Besirbellioglu BA (2005) Gram negative bacterial resistance to gram negative bacteria for cephalosporins in community acquired infections in Turkey. J Chemother 17: 61-65.

9. Zarrilli R, Giannouli M, Tomasone F, Triassi M, Tsakris A (2009) Carbapenem Resistance in Acinetobacter baumannii: the molecular epidemic features of an emerging problem in health care facilities. J Infect Dev Ctries 3: 335-341. doi: $10.3855 /$ jidc. 240

10. Meyer E, Schwab F, Gastmeier P, Rueden H, Daschner FD (2006) Surveillance of antimicrobial use and antimicrobial resistance in German intensive care units (SARI): a summary of the data from 2001 through 2004. Infection 34: 303-309.

11. Garner JS, Jarvis WR, Emori TG, Horan TC, Hughes JM (1988) CDC definitions for nosocomial infections, 1988. Am J Infect Control 16: 128-140.

12. Clinical and Laboratory Sstandards Institute (2011) Performance standards for antimicrobial susceptibility testing. Twenty-first informational supplement, M100-S21. C1SI: Wayne, PA.

13. Magiorakos AP, Srinivasan A, Carey RB, Carmeli Y, Falagas ME, Giske CG, Harbarth S, Hindler JF, Kahlmeter G, OlssonLiljequist B, Paterson DL, Rice LB, Stelling J, Struelens MJ, Vatopoulos A, Weber JT, Monnet DL (2012) Multidrugresistant, extensively drug-resistant and pandrug-resistant bacteria: an international expert proposal for interim standard definitions for acquired resistance. Clin Microbiol Infect 18: 268-281.

14. Meng X, Dong M, Wang DI, He J, Yang C, Zhu L, Sun M (2011) Antimicrobial susceptibility patterns of clinical isolates of gram-negative bacteria obtained from intensive care units in a tertiary hospital in Beijing, China. J Chemother 23: 207-210.

15. Sardan YC (2009) Surveillance Report of Hospital Infections from Turkey; 2006-2007. Turkish Journal of Hospital Infections 13: 215-269.

16. Erdem H, Dizbay M, Karabey S, Kaya S, Demirdal T, Koksal I, Inan A, Erayman I, Ak O, Ulu-Kilic A, Karasahin O, Akbulut A, Elaldi N, Yilmaz G, Candevir A, Gul HC, Gonen I, Oncul O, Aslan T, Azak E, Tekin R, Kocak Tufan Z, Yenilmez E, Arda B, Gungor G, Cetin B, Kose S, Turan H, Akalin H, Karabay O, Dogan-Celik A, Albayrak A, Guven T, Celebi G, Ozgunes N, Ersoy Y, Sirmatel F, Oztoprak N, Balkan, II, Bayazit FN, Ucmak H, Oncu S, Ozdemir D, Ozturk-Engin D, Bitirgen M, Tabak F, Akata F, Willke A, Gorenek L, Ahmed SS, Tasova Y, Ulcay A, Dayan S, Esen S, Leblebicioglu H, Altun B, Unal S (2013) Withdrawal of Staphylococcus aureus from intensive care units in Turkey. Am J Infect Control 41: 1053-1058. doi: 10.1016/j.ajic.2013.01.041.

17. Zhanel GG, DeCorby M, Laing N, Weshnoweski B, Vashisht R, Tailor F, Nichol KA, Wierzbowski A, Baudry PJ, Karlowsky JA, Lagace-Wiens P, Walkty A, McCracken M, Mulvey MR, Johnson J, Hoban DJ (2008) Antimicrobialresistant pathogens in intensive care units in Canada: results of the Canadian National Intensive Care Unit (CAN-ICU) study, 2005-2006. Antimicrob Agents Chemother 52: 14301437.

18. Japoni A, Vazin A, Davarpanah MA, Afkhami Ardakani M, Alborzi A, Japoni S, Rafaatpour N (2011) Ventilatorassociated pneumonia in Iranian intensive care units. J Infect Dev Ctries 5: 286-293.

19. Joseph NM, Sistla S, Dutta TK, Badhe AS, Rasitha D, Parija SC (2010) Ventilator-associated pneumonia in a tertiary care 
hospital in India: role of multi-drug resistant pathogens. J Infect Dev Ctries 4: 218-225. doi:10.3855/jidc.634

20. Gopal Katherason S, Naing L, Jaalam K, Imran Musa K, Nik Mohamad NA, Aiyar S,Bhojwani K, Harussani N, Abdul Rahman A, Ismail A (2009) Ventilator-associated nosocomial pneumonia in intensive care units in Malaysia. J Infect Dev Ctries 3: 704-710. doi:10.3855/jidc. 115

21. Inan A, Ozgultekin A, Akcay SS, Engin DO, Turan G, Ceran N, Dincer E, Aksaray S, Goktas P, Erdem I (2012) Alterations in bacterial spectrum and increasing resistance rates in isolated microorganisms from device-associated infections in an intensive care unit of a teaching hospital in Istanbul (2004-2010). Jpn J Infect Dis 65: 146-151.

22. Meric M, Baykara N, Aksoy S, Kol IO, Yilmaz G, Beyazit N, Mete B, Vahaboglu H (2012) Epidemiology and risk factors of intensive care unit-acquired infections: a prospective multicentre cohort study in a middle-income country. Singapore Med J 53: 260-263.

23. Planquette B, Timsit JF, Misset BY, Schwebel C, Azoulay E, Adrie C, Vesin A, Jamali S, Zahar JR, Allaouchiche B, Souweine B, Darmon M, Dumenil AS, Goldgran-Toledano D, Mourvillier BH, Bédos JP; OUTCOMEREA Study Group (2013) Pseudomonas aeruginosa ventilator-associated pneumonia. predictive factors of treatment failure. Am J Respir Crit Care Med 188: 69-76.

24. Eraksoy H, Basustaoglu A, Korten V, Kurt H, Ozturk R, Ulusoy S, Yaman A, Yuce A, Zarakolu P (2007) Susceptibility of bacterial isolates from Turkey--a report from the Meropenem Yearly Susceptibility Test Information Collection (MYSTIC) Program. J Chemother 19: 650-657.

25. Leblebicioglu $\mathrm{H}$, Cakir $\mathrm{N}$, Celen $\mathrm{M}$, Kurt $\mathrm{H}$, Baris $\mathrm{H}$, Laeuffer J (2012) Comparative activity of carbapenem testing (the COMPACT study) in Turkey. BMC Infect Dis 12: 42.

26. Gur D, Hascelik G, Aydin N, Telli M, Gultekin M, Ogulnc D, Arikan OA, Uysal S, Yaman A, Kibar F, Gulay Z, Sumerkan B, Esel D, Kayacan CB, Aktas Z, Soyletir G, Altinkanat G, Durupinar B, Darka O, Akgun Y, Yayla B, Gedikoglu S, Sinirtas M, Berktas M, Yaman G (2009) Antimicrobial resistance in gram-negative hospital isolates: results of the Turkish HITIT-2 Surveillance Study of 2007. J Chemother 21: 383-389.

27. Yuce A, Yapar N, Eren Kutsoylu O (2009) Evaluation of antibiotic resistance patterns of Pseudomonas aeruginosa and Acinetobacter spp. strains isolated from intensive care patients between 2000-2002 and 2003-2006 periods in Dokuz Eylul University Hospital, Izmir. Mikrobiyol Bul 43: $195-$ 202.

28. Rhomberg PR, Jones RN (2009) Summary trends for the Meropenem Yearly Susceptibility Test Information Collection Program: a 10-year experience in the United States (19992008). Diagn Microbiol Infect Dis 65: 414-426.
29. Turner PJ (2009) MYSTIC Europe 2007: activity of meropenem and other broad-spectrum agents against nosocomial isolates. Diagn Microbiol Infect Dis 63: 217-222.

30. Szabo D, Bonomo RA, Silveira F, Pasculle AW, Baxter C, Linden PK, Hujer AM, Hujer KM, Deeley K, Paterson DL (2005) SHV-type extended-spectrum beta-lactamase production is associated with Reduced cefepime susceptibility in Enterobacter cloacae. J Clin Microbiol 43: 5058-5064.

31. Van der Donk CF, Beisser PS, Hoogkamp-Korstanje JA, Bruggeman CA, Stobberingh EE (2011) A 12 year (19982009) antibiotic resistance surveillance of Klebsiella pneumoniae collected from intensive care and urology patients in 14 Dutch hospitals. J Antimicrob Chemother 66: 855-858.

32. Al Johani SM, Akhter J, Balkhy H, El-Saed A, Younan M, Memish Z (2010) Prevalence of antimicrobial resistance among gram-negative isolates in an adult intensive care unit at a tertiary care center in Saudi Arabia. Ann Saudi Med 30: 364-369.

33. Mohammadi-Mehr M, Feizabadi M (2011) Antimicrobial resistance pattern of Gram-negative bacilli isolated from patients at ICUs of Army hospitals in Iran. Iran J Microbiol 3: 26-30.

34. Hanberger H, Arman D, Gill H, Jindrak V, Kalenic S, Kurcz A, Licker M, Naaber P, Scicluna EA, Vanis V, Walther SM (2009) Surveillance of microbial resistance in european intensive care units: A first report from the care-icu programme for improved infection control. Intensive Care Med 35: 91-100.

35. Karlowsky JA, Jones ME, Thornsberry C, Friedland IR, Sahm DF (2003) Trends in antimicrobial susceptibilities among Enterobacteriaceae isolated from hospitalized patients in the United States from 1998 to 2001. Antimicrob Agents Chemother 47: 1672-1680.

36. Erdem H, Kurtaran B, Arun O, Yilmaz H, Celebi G, Ozkaya HD, Kaya S, Birengel S (2012) The Place and the Efficacy of Infectious Disease Consultations in the Hospitals. Infect Dis Clin Pract 20: 131-136.

\section{Corresponding author}

\section{Seniha Senbayrak Akcay}

Department of Infectious Diseases and Clinical Microbiology

Haydarpasa Numune Education and Research Hospital

Tibbiye Street No 40, 34668, Uskudar, Istanbul, Turkey

Phone: +90505 5618792

Fax: +902163475201

Email: senihasen@gmail.com

Conflict of interests: No conflict of interests is declared. 